\title{
TRIBUNAIS CONSTITUCIONAIS E CONTROLE DE CONSTITUCIONALIDADE EM RECENTES DEMOCRACIAS IBEROAMERICANAS
}

\author{
Patricia Cristina Brasil ${ }^{1}$
}

\section{Resumo}

O objetivo do presente artigo é analisar a constituição dos Tribunais Constitucionais e a organização do controle de constitucionalidade em recentes democracias ibero-americanas. Para tanto, com um resultado preliminar da investigação encartada em tese de doutoramento em Direito Político e Econômico, analisamos o processo de transição democrática, opção constitucional, estruturação dos tribunais e atribuições de controle de constitucionalidade que permearam o rearranjo geopolítico de três países iberoamericanos, a saber: México, Guatemala e Espanha. Foram pesquisados os respectivos textos constitucionais, bem como textos referenciais da ciência política de produção Ibero-Americana, estabelecendo-se uma comparação entre eles. Elaborou-se ao final, um quadro comparativo de referência a subsidiar a reflexão sobre o efetivo papel das Cortes para a Consolidação Democrática e resguardo dos direitos fundamentais. Constatou-se, entre os países pesquisados, que o modelo de democratização por ruptura é basicamente acompanhado por um novo texto constitucional, enquanto que a democratização por transição se baseia em reformas em textos pré-existentes. Outro importante fato constatado é a constitucionalização de regimes autoritários ou convivência de Tribunais Constitucionais e sistemas de controle de constitucionalidade com tais regimes, questionando-se assim, a própria relação dessas instituições com o Poder.

Palavras-chave: Controle de Constitucionalidade; Tribunais Constitucionais; Democracia; Ibero-Americana; Consolidação Democrática

\section{INTRODUÇÃO}

O período iniciado em meados da década de 1960 até a década de 1980 foi marcado por transições de regimes em todos países iberoamericanos. As transições entre regimes autoritários e democráticos foram marcadas pela predominância deste último modelo a partir de 1980. Esse rearranjo geopolítico iberoamericano acompanhava as alterações econômicas mundiais e se desenrolava sobre o tripé: globalização, reconhecimento e garantia de direitos-humanos fundamentais e alternativas à crise econômica.

Verificou-se nesse período de transição, o predomínio da opção democrática como solução de

\footnotetext{
${ }^{1}$ Doutoranda em Direito Político e Econômico pela Universidade Presbiteriana Mackenzie (bolsista CAPES/PROSUP/bolsa). Professora Universitária na Faculdade na Graduação em Direito da Metrocamp. Professora Convidada na Pós-Graduação Lato Sensu em Direito e Processo do Trabalho da Faculdade de Direito de Franca. E-mail: patcbr@gmail.com
} 
continuidade a regimes autoritários na região².

Este artigo se volta ao estudo do segundo item do tripé acima proposto, isto é, ao reconhecimento e garantia dos direitos fundamentais, como base do modelo de Estados Democráticos de Direito adotado pelos Estados Iberoamericanos no final do Século XX. Abordamos, assim, a dimensão legal dos Estados Democráticos recentemente constituídos na Ibero-América, na perspectiva de um de seus principais mecanismos de efetivação, que são os Tribunais Constitucionais e os respectivos mecanismos de controle de constitucionalidade.

Neste sentido, o texto se desenvolve abordando as democracias recentes na Ibero-América, a saber, aquelas instaladas a partir da década de 1980. Distante de esgotar o tema, escolhemos apenas 3 países iberoamericanos, que recentemente enfrentaram o desafio de ingresso tardio no regime democrático. Destes, destacamos as formas de transição, a opção constitucional, a composição e estruturação das cortes constitucionais, bem como os respectivos instrumentos de controle de constitucionalidade. Ao fim, abordaremos de forma sintética os dilemas e perspectivas da consolidação democrática em cada país.

A ideia do estudo é abordar a especificidade de cada Estado em comparação entre si, adotando-se a premissa de que o controle de constitucionalidade exercido pelos Tribunais Constitucionais é condição do Estado Democrático de Direito. Observamos, no entanto, que tais cortes por vezes existiram mesmo durante os regimes autoritários e atuaram para legitimá-los, exercendo um papel que, em tese, em nada se relaciona com a democracia. É a partir deste percurso que se busca revelar os pontos críticos da compreensão acerca dos Tribunais Constitucionais e do Controle de Constitucionalidade, no que se refere à democratização de países da periferia do capitalismo.

\section{O ESTADO DEMOCRÁTICO DE DIREITO E O CONTROLE DE CONSTITUCIONALIDADE:}

O Estado de Direito, também conhecido pela expressão rule of law é apontado por diversos teóricos como condição para a democracia (O’DONELL, 1999). Trata-se de um modelo em que necessariamente deve haver "um sistema legal que decreta e respalda os direitos e liberdades associados a esse regime (...) e faz com que nenhuma pessoa, papel ou instituição possa julgar-se de legibus solutos"(Ibidem). Significa dizer que os direitos civis, políticos e sociais, se concretizam com o respaldo de criação e garantia de um sistema legal que integra o próprio Estado e que nenhuma pessoa ou instituição pode estar acima destes direitos. Estes direitos não podem,

\footnotetext{
${ }^{2}$ Esta opção sofreu significativa influência da política externa dos Estados Unidos, que anteriormente havia colaborado para a instituição de regimes autoritários, especialmente na América Latina (GARCÍA LAGUARDIA, 2003). A alteração da dinâmica política, e o engajamento Norte-Americano para a democratização do ocidente muito se relaciona com a derrocada do inimigo externo dos Estados Unidos, isto é, a fragmentação da URSS - União Russa Socialista Soviética e sua perspectiva socialista (Idem, Ibidem)
} 
inclusive, ser anulados ou suspensos por decisão unilateral mesmo quando se tratar do conjunto de direitos que define as próprias competências e atribuições do sujeito ${ }^{3}$.

A ideia do rule of law ganhou força com a constituição dos Estados Unidos, impondo a preservação de determinadas regras jurídicas fundamentais previstas no texto constitucional e que limitam o poder do Estado. Desta forma, a preservação do texto constitucional em face de reformas casuísticas, contra leis e atos do governo, órgãos e agentes públicos exigiu não somente o estabelecimento de complexos instrumentos de alteração constitucional, como também, meios de evitar a efetivação de alterações ou práticas que o contrariem (NINO, 2003).

Trata-se da chamada supremacia da constituição como norma fundamental e fonte de validade das demais normas do ordenamento jurídico. Como consequência disso, estruturou-se um sistema de proteção contra violações pelos Poderes do Estado, no que tange à eficácia e integridade da norma constitucional. Relativamente a esse sistema de proteção, há um predomínio da via jurisdicional, isto é, da concentração, no Poder Judiciário ou em Tribunais Autônomos, do controle de constitucionalidade dos atos dos Poderes Públicos.

A despeito de que o Tribunal Constitucional em nenhum caso pretenda ser um órgão de inibição das tarefas da trilogia funcional do poder, não podemos deixar de apontar que sua presença no Estado de Direito significa um avanço em duas frentes: pelo lado dos governantes, na luta por cumprir e fazer cumprir a Constituição; por parte dos governados, ao fazer com que aqueles que exercem o poder cumpram e respeitem o marco jurídicoconstitucional que regula sua atuação, assim como os direitos dos habitantes (URIBE ARZATE, 2002).

A tradição constitucionalista reconhece a importância dos Tribunais Constitucionais como instrumento de estabilidade e garantia do Estado de Direito. Após as duas guerras mundiais, a esses Tribunais foi acrescida a feição de garantidor da efetividade dos Direitos Fundamentais e, portanto, dos Direitos Humanos, ampliando seu espectro de importância para a estabilidade dos sistemas democráticos (SILVA, 1988).

\section{O CONTROLE DE CONSTITUCIONALIDADE: ORIGEM DÚPLICE E CARACTERÍSTICAS}

O controle de constitucionalidade tem suas raízes em duas origens ou modelos distintos. De um lado o modelo americano de Marshall e de outro, o modelo Europeu proposto por Hans Kelsen.

De acordo com Horta (1991) e García Belaund (2004), o modelo de Tribunais Constitucionais proposto por Kelsen foi inicialmente recebido pelas constituições da Alemanha, da Áustria, da Tchecoslováquia e da Espanha no início do Século XX, antes da I Guerra Mundial.

\footnotetext{
${ }^{3}$ Canotilho chegou mesmo a falar em um Estado de Direito Democrático-Constitucional no segundo pós-guerra. Neste Estado de Direito Democrático-Constitucional, o Estado deve se estruturar como "uma ordem de domínio legitimada pelo povo", ressaltando o princípio da soberania popular (2009; p. 99).
} 
O modelo europeu de controle constitucional, conhecido como "controle concentrado" ou "controle abstrato", baseia-se no quadro teórico de Hans Kelsen, arquiteto do Tribunal Constitucional da Áustria, concebido em 1919 e consagrado na Constituição em 1920, e teve influência sobre o período entre guerras, o que se refletiu nos tribunais que, posteriormente, foram criados na Checoslováquia (1920) e Espanha (1931), como já mencionado ${ }^{4}$ (Tradução livre).

Nos Estados Unidos, o controle de constitucionalidade surgiu de um leading case em que o relator do caso, J. Marshall, afirmou a competência do Poder Judiciário para resguardar a Constituição. Da mesma forma, da decisão se extrai a supremacia da Constituição em relação a qualquer outro ato. Com isto, qualquer dos tribunais dos Estados Unidos passaram a ter competência e poderes para decidir acerca da constitucionalidade de leis ou atos dos demais Poderes, em qualquer caso. Desta decisão, originou-se o que foi denominado de controle difuso ou concreto de constitucionalidade, cuja influência se percebe nas Constituições Iberoamericanas.

O juiz Marshall, no caso Madison v. Marbury, explicou este pensamento da forma que se tornou clássica e que aqui transcrevemos na tradução de Rui Barbosa: É, sem dúvida, da competência e do dever do Poder judiciário interpretar a lei. Aqueles que a aplicam aos casos particulares devem, necessariamente, explaná-la, interpretá-la. Se duas leis se contrariam, os tribunais devem decidir sobre o seu âmbito de aplicação. Assim, se a lei estiver em contradição com a constituição e se tanto uma como outra forem aplicáveis ao caso, de modo a que o tribunal tenha de decidir de acordo com a lei desatendendo à constituição, ou de acordo com a constituição rejeitando a lei, ele terá, inevitavelmente, de escolher dentre os dois preceitos opostos aquele que regulará a matéria. Isto é da essência do dever judicial. Se, portanto, os tribunais devem observar a constituição, e se esta é superior a qualquer lei ordinária do poder legislativo, é a constituição e não a lei ordinária que terá de regular o caso a que ambos dizem respeito (CANOTILHO 2009; p. 894)

De acordo com García Belaund (2004), a América Latina, em sua concepção democrática, sofreu a dupla influência de ambos os sistemas e não de maneira uniforme.

Percebe-se nos países estudados, a existência do duplo controle de constitucionalidade. Significa dizer que existe previsão constitucional (originária, como na Guatemala, ou decorrente de reformas, como no caso do México) tanto de mecanismos de controle geral ou abstrato, quanto de mecanismos de controle difuso ou concreto da constitucionalidade de disposições ou atos dos Poderes Públicos.

O sistema de controle difuso, concreto ou incidental de constitucionalidade pode ser exercido por qualquer juiz que tenha de aplicar a lei a um caso concreto e se identifica com o modelo adotado nos Estados Unidos, a partir de Marshall (CANOTILHO, 2009). Enquanto que o controle concentrado, geral ou abstrato, derivado do sistema austríaco Kelseniano, define que a competência para decidir acerca da constitucionalidade das leis, disposições e atos de quaisquer dos Poderes do Estado é reservada a um único órgão originariamente (Idem, Ibidem).

\footnotetext{
4 "El modelo europeo de control constitucional, conocido como "control concentrado" o "control abstracto", reposa en la armazón teórica de Hans Kelsen, arquitecto del Tribunal Constitucional de Austria, concebido en 1919 y consagrado constitucionalmente en 1920, y que tuvo influencia en el período de entreguerras, lo que se reflejó en los tribunales que posteriormente se crearon en Checoslovaquia (1920) y España (1931), como ya se dijo" (GARCÍA BELAUND, 2004).
} 
Na perspectiva do controle concentrado, o estudo das diferentes constituições revela a possibilidade da organização desse controle de formas distintas. Em uma delas, o controle e fiscalização são atribuições de um órgão específico da jurisdição ordinária, no caso brasileiro, este órgão é o STF - Supremo Tribunal Federal (que atua tanto de forma originária para exercício de controle concentrado, como na forma de instância recursal no controle pela via difusa). Em outra possível organização, com origem no sistema elaborado por Kelsen, a fiscalização e o controle ficam a cargo de um órgão especial, criado para essa finalidade e cujas decisões teriam efeito erga omnes 5 .

A concepção kelseniana diverge substancialmente da judicial review americana: o controle constitucional não é propriamente uma fiscalização judicial, mas uma função constitucional autônoma que tendencialmente se pode caracterizar como função de legislação negativa. No juízo acerca da compatibilidade (Vereinbarkeit) de uma lei ou norma com a constituição não se discutiria qualquer caso concreto (reservado à apreciação do tribunal a quo), nem se desenvolveria uma atividade judicial (CANOTILHO, 2009; p. 892).

Segundo essa forma organizativa do controle de constitucionalidade, a Corte ou Tribunal Constitucional se constitui como um Poder à parte dos demais Poderes do Estado. Como Poder distinto, o Tribunal Constitucional gozaria de autonomia financeira, política e institucional para o exercício do controle de constitucionalidade concentrado, na forma originária, ou seja, em única instância decisória.

De acordo com Gargarella (2011), esta última forma teve sua retomada em alguns países da Europa após a segunda guerra mundial. Sobretudo na Itália, proposta por Calamandrei e na Alemanha, por Nawiaski. No entanto, essa retomada se deu de forma híbrida, mesclando aspectos do controle de constitucionalidade norteamericano com o controle concentrado austríaco ou kelseniano.

Em ambos os casos, como destaca Canotilho, o controle de constitucionalidade confere ao Tribunal ou Corte que o exerce, uma dupla dimensão de poderes. A primeira reside no reconhecimento do papel de regulador político.

Num processo contínuo de concretização e desenvolvimento das normas constitucionais, o Tribunal decide questões políticas de grande relevância político-constitucional. (...) Bem ou mal, o Tribunal Constitucional converte-se em parte institucionalizada de conformação do processo político através de atos em forma de atos jurisdicionais (CANOTILHO, 2009; p. 1289).

Além disso, as constituições passaram a reconhecer a dimensão de poder de interpretação, a ser exercido sob a égide dos princípios da primazia ou supremacia da constituição e da competência decisória em última instância (idem, ibidem). Dessa forma, obrigam-se todos os demais Tribunais a seguir a leitura de constitucionalidade feita pelo Tribunal Competente. Essas dimensões se aplicam tanto à interpretação do modelo Europeu, quanto à do modelo dos Estados Unidos.

Internamente a cada sistema de controle são propostos instrumentos distintos para sua concretização,

\footnotetext{
${ }^{5}$ Trata-se de efeito pelo qual as decisões são aplicáveis de imediato à toda a sociedade.
} 
voltados para a preservação da constituição, dos direitos humanos e dos direitos e garantias fundamentais. Esses sistemas se revelam, em especial nos países ibero-americanos, como importantes instrumentos contramajoritários, característica que vem despertando a crítica de teóricos diante do fenômeno do neoconstitucionalismo marcante no início do século XXI (GARGARELLA, 2011). Isto porque, com destaca Taylor (2006) relativamente à presença de Tribunais Constitucionais em Constituições que atenderam a regimes autoritários,

Os tribunais revelaram-se longe do seu ideal democrático: não são Instituições políticas independentes e neutras, mas, em vez disso, Papel de apoio ao regime, especialmente na medida em que "o sistema jurídico não é incompatível com o uso do direito como instrumento para dominação por grupos de elite "(TRUBEK e GALANTER 1974, 1083 apud TAYLOR, 2006)

Para a compreensão dessas características controversas, passamos à análise dos sistemas de controle em alguns países ibero-americanos. Como destacam os estudos de O’Donnell $(1994,1998)$ toda transição de regime apresenta peculiaridades quanto às circunstâncias materiais em que ocorrem e aos respectivos desdobramentos com vistas à consolidação democrática. Lembramos aqui que o nosso estudo se volta aos Tribunais Constitucionais e ao Controle de Constitucionalidade em democracias recentes na América Latina. Desse modo, para abordarmos o tema, é necessário compreender as condições em que se processou a transição, como essa transição repercutiu na opção constitucional e no modelo adotado para a organização do controle de constitucionalidade e respectivos mecanismos ou formas de atuação em cada um dos Estados selecionados.

\section{O CONTROLE DE CONSTITUCIONALIDADE E O TRIBUNAL CONSTITUCIONAL NO MÉXICO}

\section{A transição mexicana}

A Constituição Mexicana completou 100 anos em fevereiro de 2017. Conhecida como Constituição de Quéretaro, ela foi produto de uma assembleia constituinte realizada entre dezembro de 1916 e janeiro de 1917, sob a convocação de Venustiano Carranza, Primeiro Chefe do Exército Constitucionalista. Tratou-se de produto da Revolução Social Mexicana (Guerra Civil de 1914 a 1917), após a invasão dos EUA, em que os militares assumiram o Governo (MIDDLEBROOK, 1998).

O texto da Constituição de Quéretaro foi pioneiro no reconhecimento de direitos sociais, antes mesmo da Constituição de Weimar (FIX-ZAMUDIO, 2003). No entanto, esse texto respaldou um regime autoritário que seguiu com certa estabilidade até meados da década de 1960. A estabilidade se deveu em grande parte ao controle sobre o pluralismo sócio-político e sobre a mobilização política de massa, através de um sistema de inclusão social e do controle sobre o alcance de reformas (MIDDLEBROOK, 1998). 
O regime autoritário, como reflexo da revolução social mexicana, beneficiou-se do trabalho organizado e do apoio das massas, como bases de legitimação. Esses atores ingressaram no PRI - Partido Revolucionário Institucional que, afiliado ao governo, funcionou como fonte de legitimidade política (idem, ibidem).

Além disso, o processo revolucionário formou uma coalização pelo consenso duradouro sobre a ação política e pelo objetivo comum de desenvolvimento econômico. A coalização, no entanto, era formada por um agrupamento heterogêneo de atores e interesses concorrentes. Sua manutenção se baseava exclusivamente em torno desse consenso estabelecido sobre a necessidade de desenvolvimento e da contenção da ação política de massa. Revela-se um consenso interelites de contrarrevolução, nos moldes observados no Brasil (FERNANDES, 2006). Esse regime foi, portanto, dominado pela elite organizada.

Essa organização contrarrevolucionária foi marcada e garantida pelo controle estatal sobre as organizações dos trabalhadores, como sindicatos e organizações camponesas. Tais ações restringiam a ação oposicionista, fazendo com que o PRI funcionasse quase como partido único.

É de se notar que, assim como na terceira fase do regime militar no Brasil, as eleições foram mantidas como mecanismo de validação formal do regime, embora, de fato, não permitissem a real disputa e a paridade entre os candidatos. Tratava-se de eleições tuteladas, respaldadas por instituições bem estruturadas. A eficácia desse controle dos mecanismos de oposição e organização de massa garantiu que o regime autoritário no México fosse relativamente contido no que se refere ao uso da repressão (MIDDLEBROOK, 1998).

A estabilidade do regime autoritário se viu ameaçada pela grave crise econômica iniciada na década de 1960, que culminou com os choques do Petróleo, assinalando o fim do milagre econômico mexicano. Em 1968, as pressões sócio-políticas pela democratização e criação de novas oportunidades de participação culminaram na ocupação do campus da UNAM - Universidade Nacional Autónoma Del México e no Massacre de Tlatelolco ${ }^{6}$. No mesmo período, emergiram organizações partidárias clandestinas, tanto de esquerda quanto de direita, que faziam oposição ao governo. Organizaram-se ainda, guerrilhas urbanas e rurais no México, contra o controle das manifestações de massa e dos camponeses (idem, ibidem).

O esfacelamento da base popular de apoio, a emergência das manifestações sociais diante da crise econômica, a apatia popular em relação ao processo eleitoral e o enfraquecimento do PRI, renderam urgência ao processo de liberalização do regime, como forma de conter aquilo que Fernandes denomina de revolução contra a ordem (2006). Assim, em 1977 foram iniciadas reformas políticas no sentido de retomar a legitimidade do regime, mediante a incorporação de elementos da oposição política no sistema partidário oficialmente

\footnotetext{
${ }^{6}$ Os Estudantes que ocupavam a UNAM organizaram uma grande manifestação no centro da cidade de Tlatelolco contra o governo e foram violentamente reprimidos pelas forças militares por determinação do General Diáz Ordaz. Não há consenso sobre os números, o governo afirma que foram 40 mortos, já os movimentos sociais estimam mais de 1000 jovens assassinados pela repressão à manifestação de 02 de outubro de 1968 (MIDDLEBROOK, 1998).
} 
reconhecido.

Com efeito, as reformas propiciaram o aumento do número e da diversidade ideológica dos partidos políticos oficialmente registrados para o processo eleitoral. Também foram alteradas as regras de eleição, aumentando a representação de partidos de oposição na Câmara dos Deputados Federais, Estados e Municípios. Outra importante alteração foi a garantia e expansão do acesso aos meios de comunicação de massa pelos partidos de oposição. Pretendeu-se, com isso desencorajar a fraude eleitoral e a abstenção dos eleitores.

Nota-se, assim, que a transição mexicana à democracia se deu de forma pactuada e gradativa, sem a opção por uma nova constituição. Essa transição foi se aperfeiçoando por uma série de reformas na Constituição de 1917. Essas reformas operadas nas décadas de 1970, 1980 e 1990 garantiram a transição para a democracia sem ruptura, conformando interesses não hegemônicos. De 1997 até hoje, a constituição mexicana sofreu mais de 15 reformas, dentre as quais, algumas relativas à competência e à formação da Suprema Corte Mexicana.

É de se notar que não houve a convocação de uma Assembleia Constituinte encarregada de elaborar uma nova Constituição, mas reformas elaboradas pelo próprio Legislativo.

\section{O Tribunal Constitucional Mexicano}

Segundo Aguillar López, o Tribunal Constitucional mexicano tem suas origens ainda na Corte Real, em Ario de Rosales, Michoacán, no ano de 1815, sob a denominação de Supremo Tribunal de Justiça. A ideia já se pautava no reconhecimento de uma norma fundamental e no respeito às garantias individuais, mas originalmente se orientava pelo respeito à legalidade na relação entre Estados e Governados (2010). Em sua evolução, foi instaurada a corte suprema na Constituição de 1857, reproduzida na constituição de Quéretaro, em 1917. Posteriormente, chegou-se à figura da Suprema Corte de Justiça da Nação, convertida em Tribunal Constitucional pelas reformas de 1994, conforme ilustra o esquema a seguir (idem, ibidem).

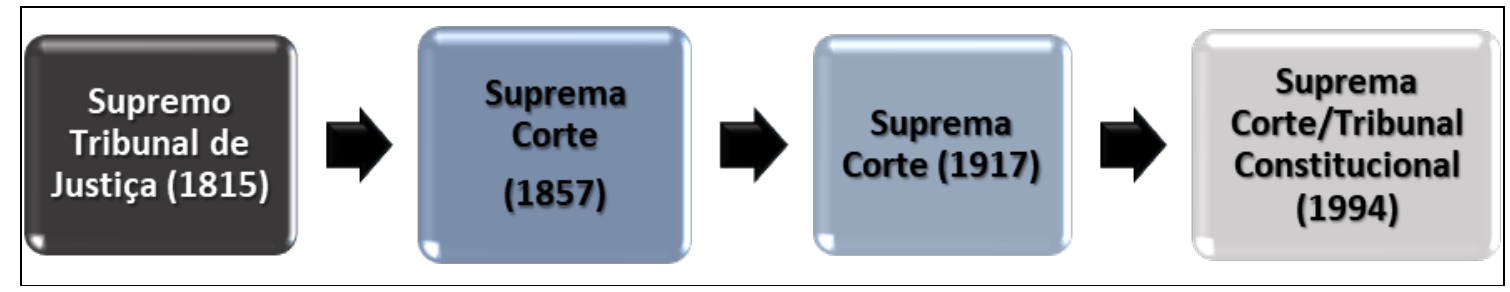

Fonte: elaboração própria.

Concentrando nossa análise na Suprema Corte mexicana convertida em Tribunal Constitucional, focamos nas reformas de 1994 e sua repercussão na organização e estrutura da casa e nos mecanismos e formas de controle de constitucionalidade. Não podemos, no entanto, deixar de registrar sua existência mesmo durante o regime autoritário. 
O Tribunal Constitucional mexicano, após a reforma de 1994, passou a ser composto por 11 Ministros, escolhidos pelo Presidente da República, com aprovação pelo Senado, à semelhança do que ocorre no Brasil. Sua atuação é dividida entre duas turmas. As turmas de julgamento, por sua vez, se organizam e subdividem em uma para assuntos civis e penais, e outra para assuntos administrativos e laborais. A duração do mandato de cada Ministro é de 15 anos, sob o regime de inamovibilidade. O Tribunal integra a estrutura do Poder Judiciário, seguindo, portanto, influências do modelo norte-americano (MÉXICO, 2017).

A competência do tribunal passou a abranger o tratamento de Controvérsias constitucionais entre os entes da federação e entre seus órgãos e agentes, salvo em matéria eleitoral; o processamento e julgamento da ação abstrata de constitucionalidade, entre outros pontos. Possui, desta forma, características de controle concentrado de constitucionalidade, não predominante.

\section{O Controle de Constitucionalidade no México:}

O controle de constitucionalidade no México é realizado através de sete mecanismos distintos, previstos constitucionalmente, a saber: juízo político (art. 111); procedimento de Investigação da Suprema Corte (art. 97); controvérsias Constitucionais (art. 105); juízo de proteção (art. 103 e 107); ação abstrata de constitucionalidade (art. 105); juízo de proteção de direitos políticos e eleitorais (art.99); juízo de revisão constitucional eleitoral (Ley General de Medios de Impugnação en Materia Eleitoral).

Esses mecanismos são frutos do aperfeiçoamento do controle de constitucionalidade promovido pelas recentes alterações na Constituição. Alterações essas de tal magnitude que conferem o status de nova Constituição à Constituição de Querétaro (FIX-ZAMUDIO, 2003).

Dentre as principais reformas, destacamos a ocorrida em 1982, que preservando o processo bicameral para aplicação da sanção de perda de cargo, introduziu a inabilitação para funções públicas. Submetem-se a essas penalidades os altos funcionários públicos que detinham imunidade constitucional (eliminada). De acordo com a reforma de 1982, também outros servidores públicos de menor hierarquia e titulares de empresas públicas podem ser submetidos a esse juízo político e de responsabilidade. A ideia era ampliar o combate à crescente corrupção no país (idem, ibidem).

Além disso, previu-se a ampliação do juízo para proteção dos direitos políticos eleitorais dos cidadãos e a ação de revisão constitucional eleitoral (idem, ibidem).

No que se refere ao procedimento de investigação, a Reforma de 1982 estendeu a atribuição da Suprema Corte em matéria eleitoral, facultando-lhe a praticar, de ofício, averiguação de fatos que constituam violação do voto público e que possam colocar em dúvida a legalidade do processo eleitoral (idem, ibidem). O procedimento decorre da tradicional separação dos direitos fundamentais pela doutrina e pela jurisprudência mexicanas entre 
Direitos Civis e os de Caráter Político. Assim, os direitos civis corresponderiam às garantias individuais ou direitos do homem, estes tutelados pelo juízo de amparo, enquanto que os direitos políticos, portanto, não poderiam ser tutelados pelo mesmo juízo de amparo, passando a ser abarcados pelo juízo de proteção aos direitos políticos. Após a sua criação, foram registradas 7.507 impugnações apresentadas ao Juízo de Proteção de Direitos Políticos e Eleitorais apenas na eleição de 1997 (FIX-ZAMUDIO, 2003).

Quanto ao chamado Juízo de Amparo, equivalente ao mandado de segurança em nosso ordenamento jurídico, a reforma de 1982 teve por escopo o combate à demora no julgamento dos processos. A finalidade precípua era garantir a efetiva proteção dos direitos fundamentais. Não se constitui efetivamente como um controle da constituição, mas sim de atos de autoridades públicas que configurem lesão ou ameaça de lesão a direitos fundamentais (idem, ibidem; AGUILLAR LÓPEZ, 2010).

Já as reformas de 1995 e 1996 introduziram os conflitos de atribuição entre órgãos e poderes públicos, por meio da criação da ação abstrata de constitucionalidade. A ação, inspirada no modelo europeu, objetiva permitir que minorias parlamentares impugnem atos de organismos de justiça constitucional e as disposições aprovadas pela maioria parlamentar (Áustria, Espanha, Portugal, etc.). A essência é garantir a aplicação da constituição. $\mathrm{O}$ instrumento não requer uma violação em concreto. São legitimados a propô-la os titulares dos Poderes Públicos, de organismos jurisdicionais de proteção de direitos humanos, o Procurador Geral da República, etc. Para serem admissíveis, devem ser manejadas contra norma já devidamente publicada. Em se tratando de leis eleitorais, os Partidos Políticos são legitimados exclusivos à proposição da ação abstrata de constitucionalidade (FIX-ZAMUDIO, 2003; AGUILLAR LÓPEZ, 2010).

A inovação no controle constitucional mexicano se deu na adoção de Comissões de Direitos Humanos, nos moldes do ombudsman escandinavo. Essas comissões apoiam e auxiliam os organismos jurisdicionais de proteção aos direitos humanos. São exemplos dessa atuação a Comissão Nacional de Direitos Humanos; a Defensoria dos Direitos Humanos da UNAM; a Procuradoria Geral da República e Ministério Público Federal, entre outros (FIX-ZAMUDIO, 2003; AGUILLAR LÓPEZ, 2010). Essa tendência também se repetiu tanto no controle de constitucionalidade Espanhol, quanto no Guatemalteco.

As reformas são reconhecidas por Valadés e Carbonell (2003) como imprescindíveis ao aperfeiçoamento e consolidação democráticos, para atender uma série de inquietudes e reacomodações sociais que devem ser reguladas pela Constituição. No entanto, no caso do México, não escapam à crítica de FixZamudio (2003), Aguillar López (2010) e Uribe Arzate (2004).

É de se notar que as reformas recentes na Constituição Mexicana apenas incluíram novos mecanismos e alterações estruturais no controle de constitucionalidade originalmente previsto. 


\section{O TRIBUNAL CONSTITUCIONAL E O CONTROLE DE CONSTITUCIONALIDADE NA GUATEMALA}

\section{A Transição Guatemalteca}

Ao contrário do que ocorreu no México, a transição Guatemalteca se deu pela via da ruptura. Um golpe de Estado em 1982, deu origem à transição democrática, cujo marco foi a promulgação de uma nova Constituição em 1985. O golpe foi a reação política e popular contra o abuso de práticas eleitorais fraudulentas, o fracionamento das forças democráticas e a desordem e corrupção na administração pública. Num contexto de aprofundamento da crise econômica, também se instalou uma crise de terras e de conflitos étnicos que levaram à formação da Unidade Revolucionária Nacional Guatemalteca - URNG. A URNG se moveu, sobretudo, em reação ao genocídio maia promovido pelos Estados Unidos, país que colaborou com as atividades de contrarrevolução até 1985 (GARCIA LAGUARDIA, 2003).

Por outro lado, tal qual ocorrido no México, a transição ocorreu no contexto internacional de incentivo Norte-Americano à retomada da democracia como sistema desejável aos países em que antes havia apoiado regimes autoritários. Especificamente na Guatemala, acrescentou-se a forte presença da Organização das Nações Unidas no acompanhamento dessa abertura democrática.

Com a revolução democrática, editou-se uma lei específica para eleição de uma Assembleia Nacional Constituinte encarregada de elaborar uma nova Constituição. A Nova Constituição da Guatemala foi promulgada em 31 de maio de 1985, instalando-se o Congresso da República e tomando posse o novo Presidente civil eleito. A Assembleia Constituinte se dissolveu após aprovar a nova Constituição, a Lei Eleitoral e de Partidos Políticos e a Lei de Amparo, Exibição Pessoal e de Constitucionalidade.

A nova Constituição então contava com mais de 221 artigos, 22 disposições transitórias e finais, que necessitava de mais de 40 leis secundárias para ser regulamentada e que até 1993 não se tinha a edição (GARCÍA LAGUARDIA, 2003).

Editada em um momento de euforia democrática, após um longo período de governos autoritários, na sua maioria militares, a Constituição da Guatemala teve como marca a ecleticidade. Essa pluralidade de interesses relegou à nova Constituição um caráter bastante heterogêneo, haja vista a necessidade de conformação da multiplicidade de feições esboçadas na constituinte. Ademais, dado aos interesses ecléticos na sua formação e diante da necessidade da formação de um consenso, restaram inúmeros dispositivos de eficácia contida ou dependente de regulamentação, nos moldes do ocorrido na Constituição Brasileira de 1988 (idem, ibidem).

A preocupação em consagrar e garantir os direitos humanos em um sistema democrático trouxe a marca 
da expressa consagração da ruptura em várias partes do texto Constitucional, que ressaltam ainda, a consolidação do regime democrático e do sistema de legalidade (idem, ibidem). Neste sentido, foi prevista a Criação de uma Corte Constitucional, no modelo predominantemente Austríaco, isto é, como órgão independente e autônomo em relação aos demais Poderes do Estado, não integrando a estrutura do Poder Judiciário. Modelo este que, também como ocorrido no México, previu uma mescla com o sistema norte-americano, ao conferir, além do controle concentrado de constitucionalidade, a possibilidade do exercício do controle difuso.

\section{A Corte Constitucional Guatemalteca:}

A Corte Constitucional Guatemalteca foi prevista no art. 268 da Constituição de 1985, que tratou de conferir autonomia administrativa independência orçamentária e caráter permanente à Corte Constitucional. Desta feita, o órgão competente para a guarda e análise de questões constitucionais foi constituído como um Poder autônomo em relação aos demais poderes do Estado, inclusive o judiciário, isto é, com capacidade de autogestão e orçamento próprio. Sua função precípua é examinar a conformidade das disposições legais em relação aos preceitos constitucionais (GUATEMALA, Corte Constitucional).

Por determinação constitucional, a Corte é composta de 5 magistrados titulares e 5 suplentes. No entanto, quando se tratar de ação de inconstitucionalidade contra a Corte Suprema de Justiça, o Congresso da República, o Presidente e o Vice Presidente da República, serão escolhidos mais dois magistrados entre os suplentes, a completar o número exigido de 7. Os magistrados são escolhidos por seus pares para um mandato de 5 anos. Esses magistrados são assim distribuídos: um pela Corte Suprema de Justiça; um magistrado pelo Congresso da República; um magistrado pelo Presidente da República no Conselho de Ministros; um magistrado pelo Conselho Superior Universitário da Universidade de San Carlos de Guatemala e um magistrado pela Assembleia do Colegio de Advogados, com os respectivos suplentes (GUATEMALA, Corte Constitucional).

Destaca-se ainda, a previsão de participação de organismos independentes dos órgãos do Estado, como a Universidade e a Assembleia dos Advogados (GARCÍA LAGUARDIA, 2012).

Quanto aos magistrados que compõem a corte, o Decreto 1/86 da Assembleia Nacional Constituinte estabeleceu que deveriam ser escolhidos entre pessoas com experiência no exercício da atividade pública, magistratura ou docência universitária. Além disso, previu-se a garantia da inamovibilidade e a imunidade por opiniões expressas no exercício do cargo. Também se estabeleceu uma série de condutas incompatíveis com o exercício da magistratura, como, por exemplo, a direção partidária e sindical, entre outras (GUATEMALA, Decreto 1-86, LAEPC).

A presidência da casa é anualmente alternada entre os seus membros, seguindo a ordem decrescente de idade, de forma continua (idem, ibidem). 
Como destaca García Laguardia (2012), tal institucionalização não bastou para evitar crises e questionamentos acerca da Corte, quanto a interferências políticas e de grupos de interesses em seu funcionamento. $\mathrm{O}$ autor aponta, ainda, a atuação da Corte no sentido de impedir a concretização de um golpe de Estado em 1993, intentado pelo então presidente da república, Jorge Serrano Elías. A atuação da Corte neste caso, contou com o apoio do Ministro da Defesa e das Forças Militares, conforme previsão constitucional. Por tudo isso Garcia Laguardia (2012) afirma que a consolidação democrática na Guatemala é um processo ainda não finalizado.

\section{O Controle de Constitucionalidade Guatemalteco:}

Previsto nos art. 226 e 257 da Constituição, o controle de constitucionalidade na Guatemala se dá tanto pela via concentrada, quanto pela via difusa ou concreta. No que se refere à via concreta, o controle pode ser total ou parcial e tem lugar durante todo o processo, em qualquer fase, juízo, instância e causa. No entanto, deve ser suscitado antes de proferida a sentença, na forma de ação, exceção ou incidente processual. Quanto ao controle concentrado e abstrato, opera-se nas ações próprias contra leis, regulamentos ou disposições de caráter geral, que contenham vício parcial ou total de inconstitucionalidade (GUATEMALA, Corte Constitucional).

No exercício do controle concentrado e abstrato de constitucionalidade a Corte Constitucional é competente para processar e julgar as impugnações interpostas contra leis ou disposições de caráter geral, objetadas parcial ou totalmente de inconstitucionalidade; para conhecer e resolver qualquer conflito de jurisdição em matéria de constitucionalidade; para emitir opinião sobre a inconstitucionalidade das leis vetadas pelo Executivo alegando inconstitucionalidade; atuar, opinar e conhecer dos assuntos de sua competência estabelecidos na Constitução; regulamentar a reforma das leis constitucionais previamente a sua aprovação por parte do Congresso; emitir opinião sobre a constitucionalidade dos projetos de lei a pedido do Congresso; conhecer dos conflitos de competência entre os organismos e entidades autônomas do Estado; consolidar a doutrina e os princípios constitucionais que se vão assentando em razão das resoluções de amparo e de inconstitucionalidade das leis, mantendo atualizado o boletim jurisprudencial; emitir opinião sobre a constitucionalidade dos tratados, convênios e projetos de lei, a requerimento de qualquer organismo do Estado.

Já no exercício de competência difusa ou concreta, caberá à Corte Constitucional funcionar originariamente como Tribunal Extraordinário de Amparo, nas ações interpostas contra o Congresso da República, a Corte Suprema de Justiça, o Presidente e o Vice-presidente da República. Caberá ainda, à Corte Constitucional, em caráter recursal, julgar a apelação de todos os amparos interpostos ante qualquer dos tribunais de justiça; julgar a apelação de todas as impugnações contra as leis tidas por inconstitucionais em casos concretos, em qualquer juízo. 
Relativamente ao juízo de amparo, assim como na Constituição Mexicana, assemelha-se ao instituto do Mandado de Segurança existente no sistema brasileiro. Como destaca García Laguardia, o sistema de controle de constitucionalidade Guatemalteco se fundamenta no tripé: habeas-corpus, juízo de amparo e controle abstrato e concentrado de constitucionalidade.

De acordo com Recinos Toledo (2016), a Constituição de 1985 não foi a primeira a tratar de controle de constitucionalidade na Guatemala, registrando-se a previsão contida no artigo 85 da Constituição de 1879, com as reformas de 1927.

\section{O TRIBUNAL CONSTITUCIONAL E O CONTROLE DE CONSTITUCIONALIDADE NA GUATEMALA}

\section{A Transição Espanhola}

Montilla-Martos (2003) destaca que o processo Constituinte Espanhol foi atípico, derivado do processo de transição de uma ditadura violenta e duradoura para um sistema democrático, após a morte do General Franco. A ditadura de Franco se iniciou em 1939 e passou por várias fases. Iniciou-se com tendência facista após a guerra-civil espanhola, recebendo forte apoio da Igreja Católica, por meio da opus day. Assim como no México, a ditadura recebeu apoio das elites espanholas que, com a derrota do facismo após a segunda-guerra mundial, buscaram evitar o isolamento, afastando-se das ideias originais do regime. Em 1953, já distanciado do facismo, o regime Franquista obteve o reconhecimento mundial.

Ao final da década de 1957, a Espanha passou a viver uma grave crise econômica. No entanto, foi somente em meados da década de 1960 que se iniciou um processo gradual de abertura, promulgando-se em 1966 uma nova Lei Orgânica do Estado, restaurando-se a Monarquia em 1969 e, em 1973, nomeou-se o Presidente do Governo. Em 1975, o General Franco faleceu e, então, o rei Juan Carlos I, no ano seguinte, nomeou Adolfo Suaréz como Presidente do Governo.

Suaréz se encarregou do desmonte das estruturas franquistas: autodissolução do parlamento (Cortes), aprovação do referendo sobre a Lei de Reforma Política, legalização dos partidos políticos, entre outros. De acordo com Serra (2014), Suaréz propôs uma reforma política de natureza democrática que foi recebida favoravelmente pelo Parlamento ainda franquista, sendo aprovada por referendo em 1976. O plano previa eleições livres para um Congresso Constituinte e a elaboração de uma nova constituição, o que ocorreu em 1978.

Serra (2014) aponta alguns fatores que facilitaram esse processo de transição, como a existência de uma substancial classe média que havia sido criada pelo desenvolvimento propiciado pela abertura econômica, após o plano de estabilização de 1959. Além disso, Serra (idem) indica o essencial papel da memória do desastre da 
guerra civil de 1939 e, finalmente, a existência de um rei que, embora indicado por Franco, era aceito pelos cidadãos e matinha o apoio dos militares. Em 1977, foi celebrado o chamado Pacto de Moncloa, marco da retomada do Estado de Direito na Espanha. Outro fator importante para essa transição, foi a formação de uma coalizão centro-direita, organizada sob a sigla UCA - União de Centro Democrática que exerceu papel significativo nas discussões constitucionais, sobretudo no embate entre continuístas e reformistas, estes últimos representados por Suaréz. (MARAVALL e SANTAMARIA, 1988). A UCD venceu as primeiras eleições livres após a transição, seguindo o desenho de O’Donnel (1998), sendo derrotada pelo PSOE - partido de oposição, nas eleições que se sucederam.

A aprovação da Constituição em 1978, por referendo, foi o marco da transição democrática espanhola pactuada após a morte do General Franco. Até 2003, a Constituição Espanhola não sofreu qualquer alteração (serra, 2014). É de se notar, que o não reconhecimento da Constituição de 78 como originária se deve ao fato de não ter sido elaborada por uma Assembleia Constituinte especialmente convocada para tal fim, mas pelo próprio parlamento que não se dissolveu após o referendo de aprovação. Referida Constituição, como destaca MontillaMartos (2003), não se apresenta como originária, pois fruto de um Congresso Constituinte

Essa transição, no entanto, não propiciou a resolução de conflitos étnicos, com atuação notável do ETA (Pátria Básica e Liberdade ou Movimento de Libertação Nacional do país Basco), em defesa da libertação do país Basco do domínio da França e Espanha. O movimento foi responsável por uma série de violentos ataques nas décadas de 1980 e 1990 na Espanha, sobretudo. Além disso, a nova constituição não impediu outra tentativa de golpe de Estado em 1981, que resultou frustrada.

\section{O Tribunal Constitucional Espanhol}

Criado pela Constituição de 1978 e regulado pela Lei Orgânica no 02/1979, a Corte Constitucional da Espanha é composta por 12 membros, cada qual com mandato de 9 anos, renovando-se $1 / 3$ das cadeiras a cada 3 anos. Os Juízes são indicados pelos poderes do Estado e nomeados pelo Rei da Espanha, sendo 4 pelo Congresso, 4 pelo Senado, 2 pelo Governo e 4 pelo Conselho Geral do Poder Judiciário, incluindo-se os suplentes. O presidente e o vice-presidente são eleitos entre os seus pares que, em seguida, propõem ao Rei a respectiva nomeação, para um mandato de três anos, permitindo-se a reeleição caso tenham ocupado o cargo por menos de três anos (ESPANHA).

A lei de regência sofreu várias alterações, entretanto, manteve-se a sua autonomia em relação aos demais poderes do Estado. As funções básicas da Corte Constitucional Espanhola são: o exercício do Controle de Constitucionalidade das Leis, a resolução de conflitos de competência centro-periferia ou de atribuições entre órgãos constitucionais, e a proteção dos Direitos Fundamentais (ESPANHA). 
A estruturação como Poder independente e autônomo, confere à Corte Espanhola a exclusividade do Controle de Constitucionalidade. Este controle é exercido com a predominância do modelo austríaco, portanto, do controle concentrado de constitucionalidade, mesclado com o modelo Norte-Americano.

\section{O Controle de Constitucionalidade Espanhol}

Observa-se que o Controle de Constitucionalidade já era previsto na Constituição Espanhola de 1912, denominado de Desputación Permanente de Cortes, o que não impediu a instauração de um regime autoritário prolongado, marcado pela violação de direitos humanos.

O Controle de Constitucionalidade na Espanha se divide em abstrato e concreto, como nos demais países estudados. O controle abstrato compreende o chamado Recurso de Inconstitucionalidade, manejado fundamentalmente por órgãos públicos e pelo defensor público. Já o controle concreto, compreende a questão de inconstitucionalidade, manejada por juízes perante o Tribunal, quando a lei base de um litígio puder ser entendida como inconstitucional.

Além desses instrumentos, o art. 161 da Constituição Espanhola inclui no rol das competências da Corte Constitucional o Recurso de Amparo (RAC) como instrumento de proteção de direitos fundamentais. Há ainda a previsão de atuação para dirimir conflitos de competência entre o Estado e as Comunidades Autônomas; o conflito de defesa de autonomia local; a declaração de inconstitucionalidade de Tratados Internacionais, as impugnações do Governo às disposições e resoluções dos órgãos das comunidades autônomas; a fiscalização da nomeação dos magistrados e a regulação de seu próprio funcionamento entre outros (SOUSA, 2012).

Se o exercício dessas competências não foi bastante a evitar uma tentativa de golpe, ao menos evitou que fosse bem-sucedida. Vê-se, segundo dados da Presidência do Tribunal, que 98\% dos casos que são julgados se tratam do exercício do juízo de amparo (ESPANHA), embora os demais casos sejam especialmente polêmicos dada a intensa questão separatista no país.

\section{CONSIDERAÇÕES FINAIS}

A propiciar um panorama analítico final, elaboramos um quadro comparativo de referência, acerca dos países estudados. A comparação engloba a forma de ruptura, a opção constitucional, a autonomia dos Tribunais Constitucionais, o modelo de Corte Constitucional e as formas de controle de constitucionalidade. 


\begin{tabular}{|c|c|c|c|c|c|c|c|}
\hline Países & Transição & $\begin{array}{c}\text { Opção } \\
\text { Constitucional }\end{array}$ & Dissolução & $\begin{array}{l}\text { Autonomia } \\
\text { dos Tribunais }\end{array}$ & $\begin{array}{l}\text { Modelo de } \\
\text { Corte } \\
\text { Constitucional }\end{array}$ & $\begin{array}{l}\text { Controle de } \\
\text { Constitucio- } \\
\text { nalidade }\end{array}$ & Ombudsman \\
\hline México & Pactuada & Reformas & Não & $\begin{array}{c}\text { Poder } \\
\text { Judiciário }\end{array}$ & $\begin{array}{c}\text { Norte- } \\
\text { Americano }\end{array}$ & $\begin{array}{c}\text { Difuso e } \\
\text { Concentrado }\end{array}$ & $\begin{array}{l}\text { Previsão de } \\
\text { Organismos }\end{array}$ \\
\hline Guatemala & Ruptura & $\begin{array}{l}\text { Assembleia } \\
\text { Constituinte }\end{array}$ & Sim & $\begin{array}{l}\text { Independente } \\
\text { e Autônomo }\end{array}$ & $\begin{array}{l}\text { Austríaco } \\
\text { (misto) }\end{array}$ & $\begin{array}{l}\text { Concentrado } \\
\text { e Difuso }\end{array}$ & $\begin{array}{c}\text { Modelo } \\
\text { Escandinavo }\end{array}$ \\
\hline \multirow{2}{*}{ Espanha } & \multirow{2}{*}{ Pactuada } & Congresso & & \multirow{2}{*}{$\begin{array}{l}\text { Independente } \\
\text { e Autônomo }\end{array}$} & Austríaco & \multirow{2}{*}{$\begin{array}{l}\text { Concentrado } \\
\text { e Difuso }\end{array}$} & \multirow{2}{*}{ Sem previsão } \\
\hline & & Constituinte & Não & & (misto) & & \\
\hline
\end{tabular}

Fonte: elaboração própria

Nota-se que os países estudados apresentam trajetórias distintas, mesclando elementos do controle de constitucionalidade austríaco e norte-americano, quanto aos instrumentos e à estrutura das cortes. Não é possível delinear nessa amostra, a existência de uma tendência ao controle por Tribunal independente ou sua vinculação ao Judiciário nas democracias ibero-americanas recentes.

Outro fator comum encontrado foi o impacto de crises econômicas sobre a estabilidade aparente dos regimes autoritários que precederam às recentes democracias estudadas. Esta interseção nos leva a concluir que a estabilidade das instituições está diretamente atrelada à estabilidade econômica, de tal sorte que a organização jurídico-política do Estado se encontra intrinsecamente relacionada ao seu sistema econômico.

Questão importante que identificamos se refere à previsão de controle de constitucionalidade. Não se trata de exclusividade dessas constituições democráticas recentes, tanto nesses países, como em outros. Mesmo em regimes autoritários foi possível identificar dispositivos constitucionais voltados para o controle de constitucionalidade, o que ocorreu também na Áustria durante as Guerras Mundiais. Desta forma, percebe-se que em momentos extremos, devemos olhar para quem tem o poder de acionar a violência do Estado, seja para garantir a ordem, seja para respaldar a sua transição e a institucionalização de regimes autoritários.

A previsão de controle de constitucionalidade, per si, indica a preocupação com as relações jurídicas internas e internacionais no conflito de interesses cotidiano à vida dos Estados. Entretanto, não se pode afirmar que, sem o apoio do uso da violência institucionalizada do Estado para garantir a eficácia das decisões dos Tribunais Constitucionais, o controle de constitucionalidade possa impedir novos golpes, nova supressão de direitos e outras violações de direitos humanos, em momentos de crise institucional.

Nos propusemos a uma análise tópica sobre o sistema dos três países, compreendendo as características que os assemelham, mas longe de esgotar o tema no que se refere às peculiaridades das democracias recentes nos países ibero-americanos. Isto porque se trata de fonte inesgotável de pesquisas e debates, ainda sem consenso no que se refere a uma teoria que estabeleça bases para se afirmar a consolidação dessas democracias recentes. 


\title{
CONSTITUTIONAL COURTS AND CONSTITUTIONAL CONTROL IN RECENT IBERO-AMERICAN DEMOCRACIES
}

\begin{abstract}
The aim of this article is to analyze the preview of the Constitutional Courts and the organization of constitutionality control in recent Ibero-American democracies. To do so, with a preliminary result of the research in $\mathrm{PhD}$ thesis in Political and Economic Law, we analyzed the process of democratic transition, constitutional option, court structure and constitutionality attributions that permeated the geopolitical rearrangement of three Ibero-American countries, Namely: Mexico, Guatemala and Spain. This article has took as font the Constitutions of these countries and studies of political science by ibero-american production. At the end, a comparative table of reference was drawn up and reflected on the effective role of the Cortes for Democratic Consolidation and safeguarding of fundamental rights. It was found among the countries surveyed that the model of democratization by rupture is basically accompanied by a new constitutional text, while the democratization by transition is based on reforms in pre-existing texts. Another important fact is the constitutionalization of authoritarian regimes or coexistence of Constitutional Courts and systems of constitutionality control with such regimes, thus questioning the very relationship of these institutions with the Power.
\end{abstract}

Keywords: Constitutionality Control; Constitutional Courts; Democracy; Iberoamerica; Democratic Consolidation

\section{REFERÊNCIAS BIBLIOGRÁFICAS}

ÁGUILLAR LOPEZ, Miguel Ángel. Génesis y Evolución del Tribunal Constitucional de Mèxico. De La Real Audiencia a la Suprema Corte. Revista Instituto Judicatura 30. indb. 09 nov. 2010. Disponível em: http://www.ij.cjf.gob.mx/publicaciones/revista/30/aguilar.pdf. Acesso em 08 mai. 2017.

BRANCO, Marcello Simão. Democracia na América Latina: os desafios da construção (1983-2002). São Paulo: FAPESP, 2007.

CAGGIANO, Monica Herman. Constitucionalismo x Democracia: um navio à deriva. Cadernos de PósGraduação em Direito: estudos e documentos de trabalho. Comissão de Pós-Graduação da Faculdade de Direito da USP, São Paulo, n. 1, 2011-. Pp. 5-23. Disponível em: http://www.direito.usp.br/pos/arquivos/cadernos/caderno_1_2011.pdf. Acesso em: 25 mar. 2017.

CANOTILHO, J.J. Direito Constitucional e Teoria da Constituição. 6a Ed. Coimbra: Almedina, 2009.

CHUIERI, Vera Karan de; GODOY, Miguel G. Constitucionalismo e Democracia: soberania e poder constituinte. Revista de Direito FGV São Paulo, 6, I, pg. 159-174, Jan-Jun 2010. Disponível em: http://direitosp.fgv.br/sites/default/files/09_1.pdf. Acesso em: 20 mai, 2017.

ESPANHA. CORTE CONSTITUCIONAL DA ESPANHA. A Corte. Disponível em: https://www.tribunalconstitucional.es/en/Paginas/default.aspx. Acesso em 10 mai. 2017.

FERNANDES, Florestan. Revolução Burguesa no Brasil. São Paulo: Globo, 2006. 
FIX-ZAMUDIO, Héctor. Evolución del Control Constitucional em México. In.: VALADÉS, Diego. CARBONELL, Miguel (Org.). Constitucionalismo Iberoamericano del Siglo XXI. Universidad Nacional Autónoma de México. Instituto de Investigaciones Jurídicas. México: Universidad Nacional Autónoma de México 2004.

FULIARO, Ana Paula. Democracia na América Latina: Enfoque Especial - alternância no poder. Tese Doutorado Faculdade de Direito da Universidade de São Paulo. 2016.

GARCÍA BELAUNDE, Domingos. Los Tribunais Constitucionales em América Latina. Corte Interamericana de Direitos Humanos. Disponível em: http://www.corteidh.or.cr/tablas/12843a.pdf. Acesso em: 27 mai. 2017.

GARCÍA LAGUARDIA, Jorge Mario. Transición Democrática y Nuevo Orden Constitucional: la Constituición Guatemalteca de 1985. In: VALADÉS, Diego. CARBONELL, Miguel (Org.). Constitucionalismo Iberoamericano del Siglo XXI. Universidad Nacional Autónoma de México. Instituto de Investigaciones Jurídicas. México: Universidad Nacional Autónoma de México 2004.

La Justicia Constitucional em Guatemala. El Estatuto del Juez Constitucional: asignatura pendiente. Universidad Autónoma de México, Instituto de Investigaciones Jurídicas, 2012. Disponível em https://archivos.juridicas.unam.mx/www/bjv/libros/7/3166/54.pdf. Acesso em: 18 mai. 2017.

GARGARELLA, Roberto. La justicia frente al gobierno: sobre el carácter contramayoritario del poder judicial. Quito: Corte Constitucional para el Período de Transición, 2011.

GARGARELLA, Roberto; CURTIS, Christian. El Nuevo Constitucionalismo Latinoamericano: promesas e interrogantes. CEPAL, Comissão Econômica para América Latina e Caribe. Santiago, Chile, nov. 2009. Disponível em: http://www.cepal.org/es/publicaciones/6162-nuevo-constitucionalismo-latinoamericanopromesas-interrogantes. Acesso em: 16 mai. 2017.

GUATEMALA. CORTE DE CONSTITUCIONALIDAD DE REPÚBLICA DE GUATEMALA. La Corte. Disponível em: http://cc.gob.gt/objetivos-y-funciones/.Acesso em 01 mai. 2017.

HORTA, Raul Machado. Jurisdição Constitucional e Os Tribunais Constitucionais. Revista Ibero-Americana de Direito Público. Rio de Janeiro, v. 4, n. 11, p. 241-246, jul./set., 2003. Disponível em: http://www.ablj.org.br/revistas/revista23/revista23\%20\%20RAUL\%20MACHADO\%20HORTA\%20\%E2\%80 \%93\%20Jurisdi\%C3\%A7\%C3\%A30\%20constitucional\%20e\%20os\%20Tribunais\%20constitucionais.pdf. Acesso em: 18 mai. 2017.

J. LINZ, Juan. An authoritarian regime: the case of Spain. In: ALLARDT, E. \& LITTUNEN, Y. (orgs.). Cleavages, ideologies and party systems: contributions to comparative political sociology. Helsinki, The Academic Bookstore, 1964, p. 291-341.

LAGI, Sara. Hans Kelsen and the Austrian Constitutional Court (1918-1929). Revista Co-Herencia, Universidade EAFIT, Vol. 9, Núm. 16 (2012). Disponível em: http://publicaciones.eafit.edu.co/index.php/coherencia/article/view/1187. Acesso em: 19 may. 2017.

MARAVALL, José Maria; SANTAMARIA, Julián. A Mudança Política na Espanha e Perspectivas da Democracia. In,: O 'DONNELL, Guillermo; SCHMITTER, Philippe C.; WHITEHEAD, Laurence. Transições do Regime Autoritário: Sul da Europa. São Paulo: Vértice Editora /Revista dos Tribunais, 1988. 
MÉXICO. Suprema Corte de Justicia de La Nación. Disponível em: https:/ /www.scjn.gob.mx/. Acesso em: 15 mai 2017.

MONTILLA MARTOS, José Antonio. Proceso Constityente y Desarrolo Constitucional Em España. In.: VALADÉS, Diego. CARBONELL, Miguel (Org.). Constitucionalismo Iberoamericano del Siglo XXI. Universidad Nacional Autónoma de México. Instituto de Investigaciones Jurídicas. México: Universidad Nacional Autónoma de México 2004.

SANTIAGO NINO, Carlos. Ética y derechos humanos: un ensayo de fudamentación. Madrid: Ariel, 1989. La constitución de la democracia deliberativa. Barcelona: Gedisa, 2003

O'DONNELL, Guillermo; SCHMITTER, Philippe C.; WHITEHEAD, Laurence. Transições do Regime Autoritário: Sul da Europa. São Paulo: Vértice Editora / Revista dos Tribunais, 1988.

Transições do Regime Autoritário: América Latina. São Paulo: Vértice Editora /Revista dos Tribunais, 1988.

Teoria Democrática e Política Comparada. Revista Dados, vol. 4, Rio de Janeiro, 1999. Disponível em: http://scielo.br/scielo.php?pid=S0011-52581999000400001\&script=sci_arttext. Acesso em: 15 out, 2015.

RECINOS TOLEDO, Carlos Alberto. Antecedentes De La Corte De Constitucionalidad En Guatemala Y Los Tribunales Constitucionales Latinoamericanos: estudio de derecho comparado. 2016. 129 f. Monografia (Graduação) - Curso de Licenciatura En Ciencias JurÍdicas y Sociales, Facultad de Ciencias JurÍdicas y Sociales, Universidad Rafael LandÍvar, Quetzaltenango, 2016. Disponível em: <http://recursosbiblio.url.edu.gt/tesiseortiz/2016/07/01/Recinos-Carlos.pdf>. Acesso em: 20 maio 2017.

SERRA, Narcis. Constitutional Reform and Civil Military Relations um Spain. In.: VASCONCELOS, Álvaro; STANG, Gerald. Constitucional Reform In Times Of Transitions. Paris: Arab Reform Iniciative, 2014.

SOUSA, Marília Nascimento de. A Reestruturação Funcional Dos Tribunais Encarregados Da Jurisdição Constitucional. Os Casos De Brasil E Espanha Disponível em: http://www.publicadireito.com.br/artigos/?cod=e586a4f55fb43a54. Acesso em: 20 mai. 2017.

TAYLOR, Matthew M. Beyond Judicial Reform: Courts as Political Actors in Latin America. Latin American Research Review, Vol. 41, No. 2, June 2006; p. 269-280. Disponível em: http://lasa4.univ.pitt.edu/LARR/prot/fulltext/vol41 no2/Taylor.pdf. Acesso em: 20 mai. 2017.

TRIBUNAL CONSTITUCIONAL DE ESPAÑA. Composición, Organización y Competências. Disponível em: https://www.tribunalconstitucional.es/es/tribunal/normativa/Paginas/Defaultaspx. Acesso em: 10 mai. 2017.

URIBE AZARTE, Enrique. El Tribunal Constitucional em México: perspectiva y possibilidad. In.: VÉGA GOMEZ, Juan; CORSO SOSSA, Edgar. Tribunales y Justicia Constitucional. Memória del VII Congreso Iberoamericano de Direito Constitucional. Instituto de Investigaciones Jurídicas. México, 2002. Disponível em: https://archivos.juridicas.unam.mx/www/bjv/libros/1/343/24.pdf. Acesso em: 05 mai. 2017.

VALADÉS, Diego. CARBONELL, Miguel (Org.). Constitucionalismo Iberoamericano del Siglo XXI. Universidad Nacional Autónoma de México. Instituto de Investigaciones Jurídicas. México: Universidad Nacional Autónoma de México 2004.

VASCONCELOS, Álvaro; STANG, Gerald. Constitucional Reform in Times Of Transitions. Paris: Arab 
Quaestio Iuris vol. 11, n. 01, Rio de Janeiro, 2018. pp. 637-657 DOI: $10.12957 /$ rqi.2018.28874

Reform Iniciative, 2014.

Trabalho enviado em 23 de maio de 2017.

Aceito em 12 de setembro de 2017. 